Article

\title{
Serrated Flow and Work-Hardening Behavior of China Low Activation Martensitic Steel (CLAM)
}

\author{
Zhiqiang $\mathrm{Xu}$ and Yinzhong Shen * \\ School of Mechanical Engineering, Shanghai Jiao Tong University, 800 Dongchuan Road, \\ Shanghai 200240, China; zhiqiang789@sjtu.edu.cn \\ * Correspondence: shenyz@sjtu.edu.cn; Tel.: +86-21-3420-7117
}

Received: 16 May 2018; Accepted: 31 May 2018; Published: 2 June 2018

\begin{abstract}
Serrated flow and work-hardening behavior (by Voce equation) of China low activation martensitic (CLAM) steel were investigated in the temperature range of $300-923 \mathrm{~K}\left(27^{\circ} \mathrm{C}\right.$ to $\left.650{ }^{\circ} \mathrm{C}\right)$. The steel exhibited serrated flow at intermediate temperatures of $573-623 \mathrm{~K}\left(300-350^{\circ} \mathrm{C}\right)$ and elevated temperatures higher than $773 \mathrm{~K}\left(500{ }^{\circ} \mathrm{C}\right)$, respectively. Type $\mathrm{A}, \mathrm{A}+\mathrm{B}, \mathrm{A}+\mathrm{C}, \mathrm{A}+\mathrm{D}$, and mild serrations were identified. The observed serrations, the plateau/peak in flow stress and a minimum in ductility suggested the occurrence of dynamic strain aging (DSA), a phenomenon due to interactions between solute atoms and dislocations during plastic deformation, at intermediate temperatures, while the mild serrations observed at high temperatures were ascribed to a combined effect of tensile deformation and dynamic recovery. The variations of work-hardening parameters including saturation stress $\sigma_{S}$, initial stress $\sigma_{I}$ and rate parameter $n_{V}$ with respect to temperatures also implied the dominance of DSA at intermediate temperatures. CLAM steel in present investigation generally displayed two-stage work-hardening behavior consisting of transient stage and stage-III. Good correlations had been presented between work-hardening parameters obtained by Voce equation and the respective experimental tensile properties, suggesting adequate applicability of Voce relationship for CLAM steel.
\end{abstract}

Keywords: CLAM steel; serrated flow; tensile flow; work hardening behavior; Voce equation; dynamic strain ageing

\section{Introduction}

Fusion energy is commonly considered as one of the most important long-term energy options. The harsh operating environment can, however, cause serious damage-irradiation swelling, hardening, and embrittlement-to materials in fusion reactors [1]. China low activation martensitic (CLAM) steel, as a reduced activation ferritic/martensitic (RAFM) steel, is thus a promising structural material for blanket modules, plasma facing components and divertors due to its attractive properties, which include relatively small thermal expansion, high thermal conductivity, and negligible irradiation swelling and embrittlement when compared to austenitic stainless steels, vanadium alloys and $\mathrm{SiC} / \mathrm{SiC}$ composites [2-4]. The development of CLAM is of great importance and will be a stepping stone for fusion reactors in the future. However, CLAM steel may be subject to the influence of dynamic strain aging (DSA), which can induce changes in material properties such as strength and ductility. Occurrences of DSA have been identified in several previous reports for certain high-Cr ferritic/martensitic (F/M) steels [5-10]. Consequently, serrated flow (the most important manifestations of DSA) and tensile properties of CLAM steel should be investigated in detail.

Besides the serrated flow behavior, tensile flow and work-hardening behavior also attract continuous scientific and technological interest on account of improving conditions for material processing, and ensuring safe performance during service [11]. Work-hardening phenomenon is related to steel 
behavior in secondary processes, and dynamic behavior after steel production in some previous reports [12-14]. Several constitutive relationships [15-19] have been proposed to depict tensile flow and work-hardening behavior of metals, while Voce relationship $[15,16]$ attracts more attention. The Voce equation $[15,16]$ can be expressed as:

$$
\sigma=\sigma_{S}-\left(\sigma_{S}-\sigma_{I}\right) \exp \left[-\left(\varepsilon-\varepsilon_{I}\right) / \varepsilon_{C}\right]
$$

where $\sigma_{S}$ represents the saturation stress, a stress at which work-hardening rate becomes zero, $\sigma_{I}$ represents the true stress at the onset of true plastic strain $\varepsilon_{I}$, and $\varepsilon_{C}$ is a strain constant. By setting $\varepsilon_{I}=0$ and $n_{V}=-1 / \varepsilon_{C}$, Equation (1) reduces to:

$$
\sigma=\sigma_{S}-\left(\sigma_{S}-\sigma_{I}\right) \exp \left(n_{V} \varepsilon\right)
$$

with three constants. The physical significance of Voce equation was interpreted by the Kocks-Mecking (K-M) phenomenological model [20-23]. Many investigations have been performed previously to describe the tensile flow and work-hardening behavior in the frame work of Voce relationship for a wide range of temperatures and strain rates, demonstrating the adequate applicability of Voce equation for different types of steel [5,24-31].

The aim of this present work is to investigate the serrated flow, tensile flow, and work-hardening behavior of CLAM steel in the frame work of Voce equation in the temperature range of $300 \mathrm{~K}$ to $923 \mathrm{~K}$ $\left(27^{\circ} \mathrm{C}\right.$ to $\left.650{ }^{\circ} \mathrm{C}\right)$, and to further understand DSA phenomena and the applicability of Voce relationship for CLAM F/M steel.

\section{Materials and Methods}

The test material studied in the present investigation was CLAM steel (HEAT-9), which was supplied by the Fission/Fusion Design Study (FDS) team affiliated to the Institute of Nuclear Energy Safety Technology, Chinese Academy of Sciences (CAS). The main chemical composition of this CLAM steel is listed in Table 1. The initial as-received CLAM steel plate was in normalizing-and-tempering $(\mathrm{NT})$ condition-normalizing at $1253 \mathrm{~K}\left(980^{\circ} \mathrm{C}\right)$ for $30 \mathrm{~min}$, followed by air cooling, and then tempering at $1033 \mathrm{~K}\left(760^{\circ} \mathrm{C}\right)$ for $1 \mathrm{~h}$ with subsequent air-cooling to room temperature.

Table 1. Chemical composition of China low activation martensitic (CLAM) steel (in wt \%).

\begin{tabular}{ccccccccccccc}
\hline $\mathbf{C}$ & $\mathbf{N}$ & $\mathbf{S i}$ & $\mathbf{O}$ & $\mathbf{S}$ & $\mathbf{P}$ & $\mathbf{B}$ & $\mathbf{M n}$ & $\mathbf{C r}$ & $\mathbf{W}$ & $\mathbf{T a}$ & $\mathbf{V}$ & $\mathbf{N b}$ \\
\hline 0.097 & 0.0092 & 0.056 & 0.004 & 0.0019 & 0.003 & 0.0012 & 0.49 & 8.85 & 1.47 & 0.12 & 0.21 & 0.01 \\
\hline
\end{tabular}

Flat tensile specimens of $10 \mathrm{~mm} \times 4 \mathrm{~mm} \times 2 \mathrm{~mm}$ in gauge dimension were cut from the steel plate. Tensile tests were conducted on an SHIMADZU AG100KN-A universal testing machine with a load accuracy of $\pm 0.3 \%$ and a maximum load of $100 \mathrm{KN}$. The specimens were tensioned at different temperatures in the range from $300 \mathrm{~K}$ to $923 \mathrm{~K}\left(27{ }^{\circ} \mathrm{C}\right.$ to $\left.650{ }^{\circ} \mathrm{C}\right)$ at the initial strain rates of $10^{-5}-2 \times 10^{-4} \mathrm{~s}^{-1}$. Notably, no strain gage was employed, and the crosshead displacement was obtained as the specimen extension. Therefore, the linear elastic part of the load-elongation data consisted of the specimen, load-train assembly, and machine frame. The combination of these elastic portions was finally subtracted from total elongation to estimate the plastic strain [5,24-26]. Consequently, the absence of an extensometer did not cause problems with the stress-strain behavior.

For tensile flow behavior in the frame work of Voce relationship, stress and plastic strain data was used with some formula to obtain true stress $(\sigma)$-true plastic strain $(\varepsilon)$ at first. Experimental $\sigma-\varepsilon$ data was fitted to the Voce equation using the Levenberg-Marquardt least square method with unknown constants as adjustable parameters. The applicability of fit was judged by a low value of Reduced Chi-Sqr $\left(\chi^{2}\right)$, which represented the mean square of the deviations of the calculated stress values from the experimental stress data. Centered difference formula was used to calculate instantaneous work 
hardening rate $(\theta)$ from the $\sigma-\varepsilon$ data at each experimental point. The methods mentioned above has been demonstrated in many previous reports $[11,24-26,31]$.

\section{Results and Discussion}

\subsection{Serrated Flow Behavior}

Engineering stress-strain curves of the CLAM steel at an initial strain rate of $2 \times 10^{-4} \mathrm{~s}^{-1}$ at temperatures ranging $300 \mathrm{~K}$ to $923 \mathrm{~K}\left(27^{\circ} \mathrm{C}\right.$ to $\left.650{ }^{\circ} \mathrm{C}\right)$ are shown in Figure 1 . Those tensile curves exhibit typical shapes at temperatures up to $773 \mathrm{~K}\left(500^{\circ} \mathrm{C}\right)$, as shown in Figure 1a, and rapid failure phenomenon after yield at temperatures higher than $823 \mathrm{~K}\left(550^{\circ} \mathrm{C}\right)$, as present in Figure $1 \mathrm{~b}$. The results also clearly indicate that serrations emerge in the temperature range of $573-623 \mathrm{~K}\left(300-350^{\circ} \mathrm{C}\right)$ and over $773 \mathrm{~K}\left(500^{\circ} \mathrm{C}\right)$, respectively. Figure 2 show some engineering stress-strain curves in the intermediate temperature range at different strain rates in CLAM steel, revealing serrated flow during tensile deformation. Based on the acceptance classification and nomenclature [5,32,33], type A serrations are periodic serrations, which show an abrupt rise in stress value followed by discontinuous drops below the general/mean level of stress-strain curves; type B serrations are slight oscillations about the general/mean level of the stress-strain curves, and often develop from type A serrations; type C serrations are stress drops that always occur below the general or mean level of the stress-strain curves; type D serrations are characterized by nearly plateaus/decrease in stress after a peak following initial rapid increase in stress value from the general or mean level of stress-strain curves. According to these definitions, different types of serrations, including tape $\mathrm{A}, \mathrm{A}+\mathrm{B}, \mathrm{A}+\mathrm{C}$, and $\mathrm{A}+\mathrm{D}$ serrations are identified. Figure $2 \mathrm{a}$ shows tensile curves in different temperatures at strain rate of $2 \times 10^{-4} \mathrm{~s}^{-1}$. Serrations of type A + D are observed at $573 \mathrm{~K}\left(300{ }^{\circ} \mathrm{C}\right)$ while type $\mathrm{A}+\mathrm{B}$ serrations are found at $598 \mathrm{~K}\left(325^{\circ} \mathrm{C}\right)$. Toward the end of the serrations at $623 \mathrm{~K}\left(350^{\circ} \mathrm{C}\right)$, type $\mathrm{A}+\mathrm{C}$ serrations are noticed. At an intermediate temperature of $623 \mathrm{~K}\left(350{ }^{\circ} \mathrm{C}\right)$, type A serrations at strain rate of $5 \times 10^{-5} \mathrm{~s}^{-1}$ followed by type $\mathrm{A}+\mathrm{C}$ serrations at $10^{-4} \mathrm{~s}^{-1}$ and type $\mathrm{A}+\mathrm{C}$ serrations at $2 \times 10^{-4} \mathrm{~s}^{-1}$ are observed, which is presented in Figure 2b. Generally, type D serrations occur at the beginning or toward the end of the serrated flow temperature range, while type $C$ serrations are often observed toward upper-end temperatures of serrated flow behavior as mixed $\mathrm{A}+\mathrm{C}$ and/or D $+\mathrm{C}$ serrations [5]. In the temperature range higher than $773 \mathrm{~K}\left(500{ }^{\circ} \mathrm{C}\right)$, as shown in Figure $1 \mathrm{~b}$, mild irregular serrations are observed. Those mild serrations are similar to typical type E serrations, which are generally changed over from type A serrations in the relatively low temperature range at high strains [32].

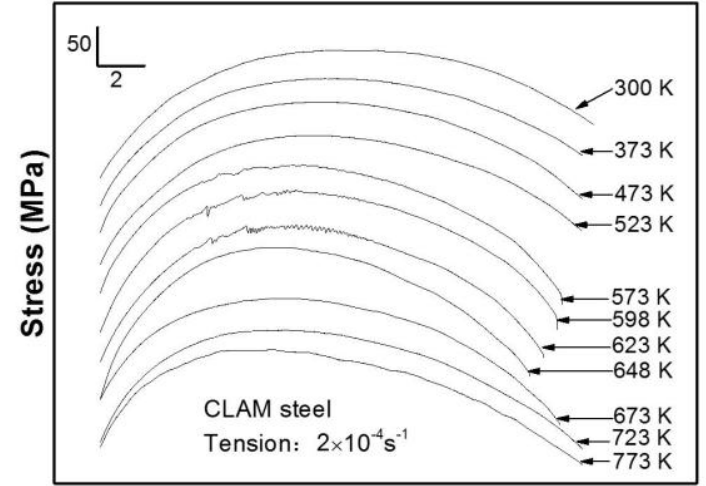

Strain (\%)

(a)

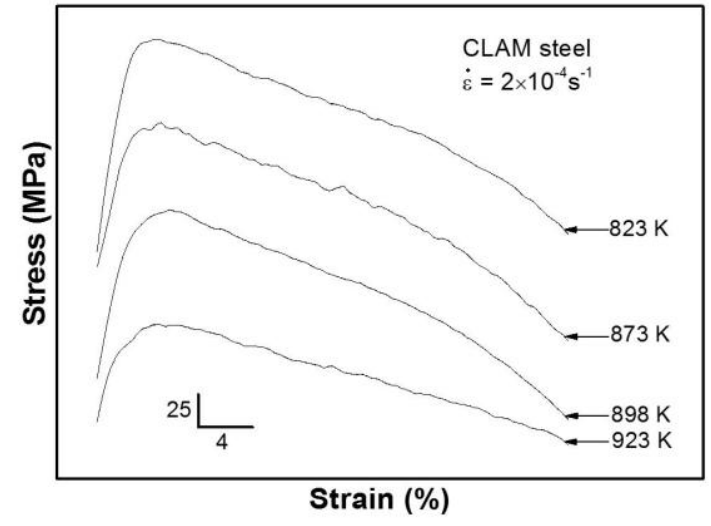

(b)

Figure 1. Engineering stress-strain curves of China low activation martensitic (CLAM) steel at different test temperatures, (a) 300-773 K, (b) 823-923 K, at an initial strain rate of $2 \times 10^{-4} \mathrm{~s}^{-1}$. 


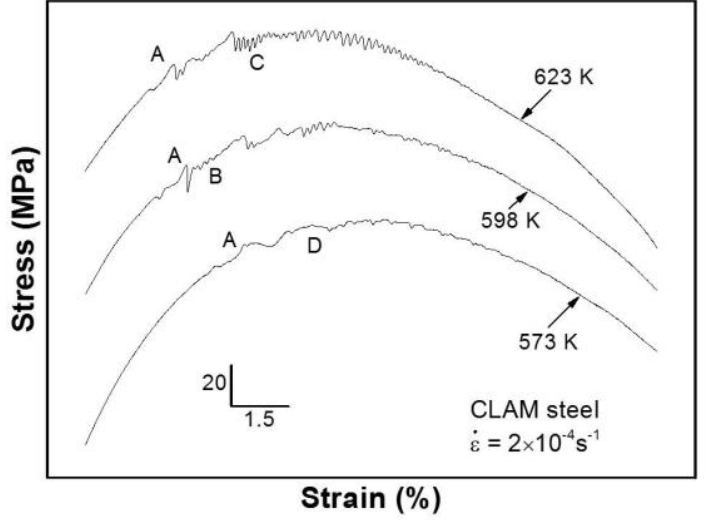

(a)

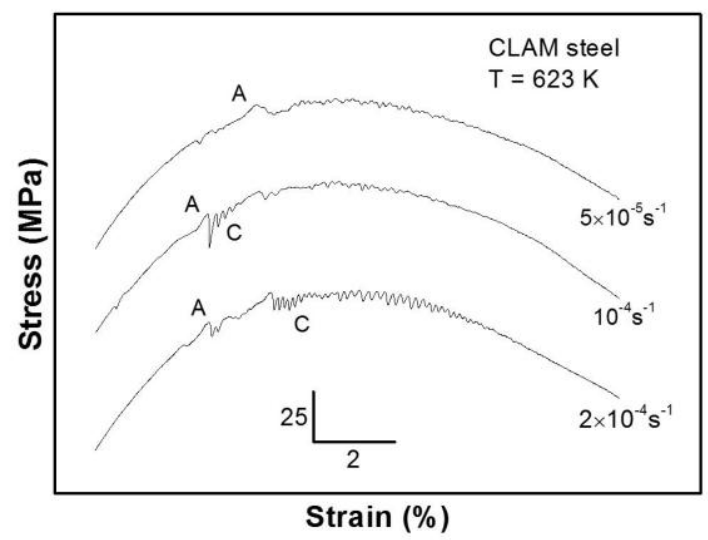

(b)

Figure 2. Parts of engineering stress-strain curves in China low activation martensitic (CLAM) steel at (a) various temperatures and (b) different strain rates, showing diverse types of serrations.

Variation of tensile properties of CLAM steel; including ultimate tensile strength (UTS), yield strength (YS), and total elongation with temperature at the initial strain rate of $2 \times 10^{-4} \mathrm{~s}^{-1}$ is shown in Figure 3. The plots in Figure 3a reveal that both UTS and YS values exhibit a decrease with increasing temperature from $300 \mathrm{~K}$ to $523 \mathrm{~K}\left(27^{\circ} \mathrm{C}\right.$ to $\left.250^{\circ} \mathrm{C}\right)$, followed by insignificant variations at an intermediate temperature range of $573-673 \mathrm{~K}\left(300-400^{\circ} \mathrm{C}\right)$ and a rapid decrease in stress values at high temperatures in the range $723-923 \mathrm{~K}\left(450-650^{\circ} \mathrm{C}\right)$. In other words, the stress values of UTS and YS exhibit a "plateau" at intermediate temperatures. Variation of total elongation with temperature, as presented in Figure 3b, generally display a decrease at temperatures from $300 \mathrm{~K}$ to $648 \mathrm{~K}\left(27^{\circ} \mathrm{C}\right.$ to $\left.375^{\circ} \mathrm{C}\right)$ followed by an increase at temperatures higher than $673 \mathrm{~K}\left(400{ }^{\circ} \mathrm{C}\right)$. Therefore, the elongation value obtains a minimum at the intermediate temperature range.

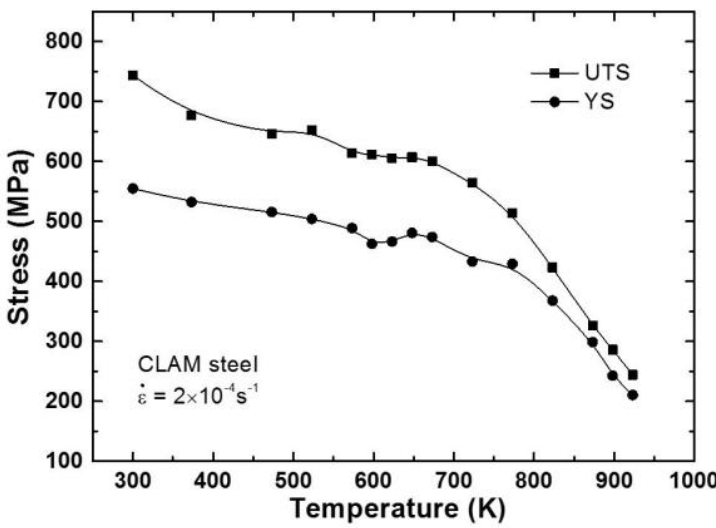

(a)

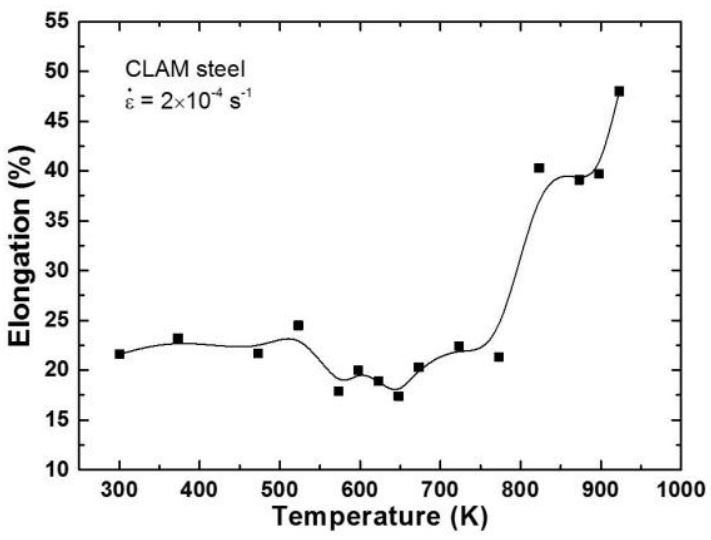

(b)

Figure 3. Variation of tensile properties with temperature at the initial strain rate of $2 \times 10^{-4} \mathrm{~s}^{-1}$ in China low activation martensitic (CLAM) steel: (a) ultimate tensile strength (UTS) and yield strength (YS); (b) total elongation.

There have been previous reports on serrated flow behavior in high-Cr ferritic/martensitic (F/M) steel. In those studies [5-8], serrations were generally observed at intermediate temperatures; different types of serrations, including type $\mathrm{A}, \mathrm{A}+\mathrm{B}, \mathrm{A}+\mathrm{C}, \mathrm{C}, \mathrm{D}, \mathrm{D}+\mathrm{C}$ and mild serrations with respect to temperature and/or strain rate were detected. Serrated flow observed in the present investigation is consistent with these previous results at intermediate temperatures though the number of stress drops is comparatively lower [5-8]. However, mild serrations are also observed in elevated temperatures in CLAM steel, which is different from these reports [5-8]. Notably, as distinct from present study, 
Vanaja investigated tensile tests for a series of reduced activation ferritic/martensitic steels, and no serrated flow was observed over the entire temperature range [34,35].

The observation about serrated flow in present CLAM steel (Figures 1 and 2) is regarded as one of the most important manifestations of DSA [5,7,32]. Other manifestations of DSA, including peaks/plateaus in flow stress and a minimum or minima in ductility [7,32], are also consistent with the results in the present investigation. Consequently, the CLAM steel in this study exhibits DSA phenomenon at intermediate temperatures. Activation energy, as a measure of energy required for appropriate solute diffusion to affect serrated flow in solid solution alloys, can be obtained in the way of calculation by model [36] or an alternate method [5,7] to understand the mechanism of serration phenomena. The obtained values of activation energy at intermediate temperatures in high-Cr ferritic/martensitic were in the range of $64-100 \mathrm{~kJ} / \mathrm{mol}$ in previous reports $[5,7,9,10]$. Based on these values, the occurrence of DSA could be attributed to locking of mobile dislocations by diffusing carbon atoms [5,7]. However, at elevated temperatures higher than $773 \mathrm{~K}\left(500{ }^{\circ} \mathrm{C}\right)$, these observed mild serrations were not considered to result from DSA. The rapid decrease of tensile flow stress and increase of ductility with increasing temperatures suggest the dominance of dynamic recovery process at high temperatures $[5,26]$. Therefore, dynamic recovery is significant during tensile test at high temperatures, which can result in a softening effect to the material; on the other hand, the continuous tensile deformation will harden the steel. Therefore, those mild serrations observed at elevated temperatures appear to be attributed to a combined effect of tensile deformation and dynamic recovery.

\subsection{Work Hardening Behavior}

Figure 4 shows typical true stress $(\sigma)$-true plastic strain $(\varepsilon)$ plots of CLAM steel obtained in the temperature range of $300-923 \mathrm{~K}\left(27-650{ }^{\circ} \mathrm{C}\right)$ at strain rate of $2 \times 10^{-4} \mathrm{~s}^{-1}$. The tendency for saturation of flow stress at high strains is illustrated in this figure. The plots indicate that $\sigma-\varepsilon$ data obtained at temperatures from $300 \mathrm{~K}$ to $823 \mathrm{~K}\left(27^{\circ} \mathrm{C}\right.$ to $\left.550^{\circ} \mathrm{C}\right)$ exhibit curvilinear behavior. However, at temperatures higher than $873 \mathrm{~K}\left(600^{\circ} \mathrm{C}\right), \sigma-\varepsilon$ data is observed to be nearly linear. The results also reveal that true flow stress exhibits a general decrease with respect to increasing temperature in the range of $300-923 \mathrm{~K}\left(27-650{ }^{\circ} \mathrm{C}\right)$. The values of flow stress show a decrease with increase at relatively low temperatures followed by a marginal change in the values at intermediate temperatures and a rapid decrease at temperatures higher than $723 \mathrm{~K}\left(450{ }^{\circ} \mathrm{C}\right)$. In intermediate temperature range of 573-673 $\mathrm{K}\left(300-400{ }^{\circ} \mathrm{C}\right)$, five $\sigma-\varepsilon$ plots seem to lie in a narrow band, intertwined with each other. This phenomenon appears to relate to the occurrence of DSA at intermediate temperatures. Besides variations in tensile stress, a general decrease in true uniform plastic strain with increase in temperature from $300 \mathrm{~K}$ to $923 \mathrm{~K}\left(27^{\circ} \mathrm{C}\right.$ to $\left.650^{\circ} \mathrm{C}\right)$ is also exhibited. Nevertheless, the values of true uniform plastic strain appear to get a minimum or minima between $773 \mathrm{~K}$ and $873 \mathrm{~K}\left(500{ }^{\circ} \mathrm{C}\right.$ and $\left.600{ }^{\circ} \mathrm{C}\right)$, which is different from some previous reports for high-Cr F/M steels [5,24]. 


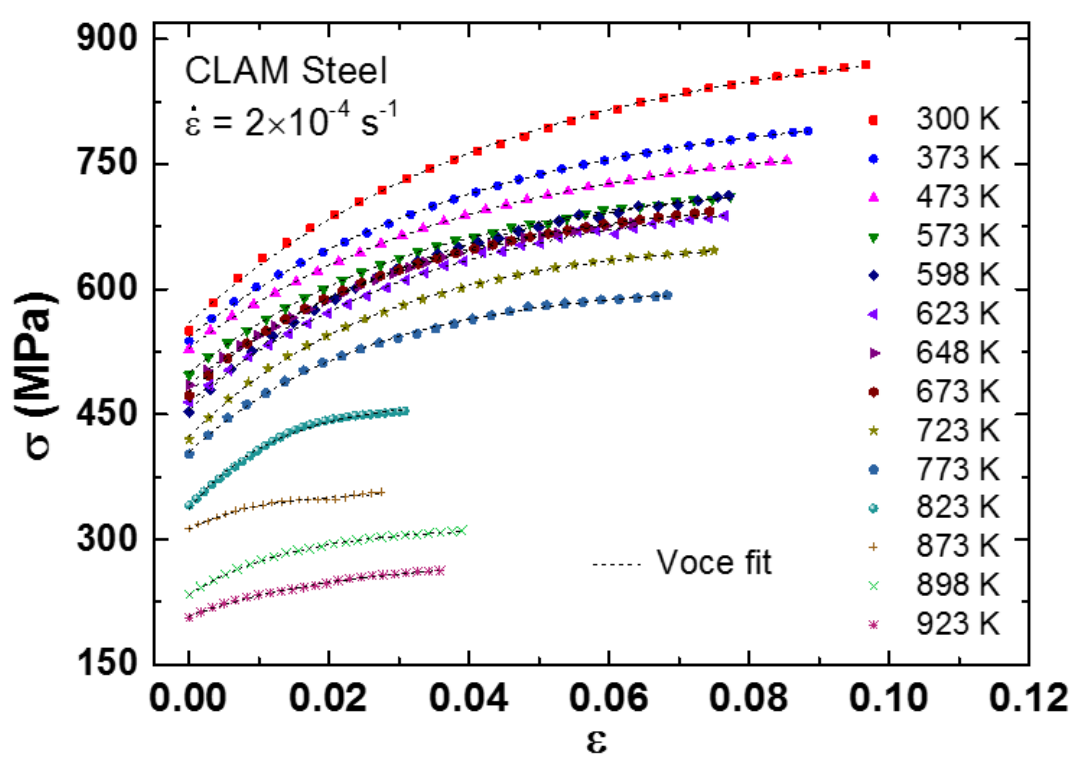

Figure 4. Voce fit to true stress $(\sigma)$-true plastic strain $(\varepsilon)$ at strain rate of $2 \times 10^{-4} \mathrm{~s}^{-1}$ in China low activation martensitic (CLAM) steel.

The fitted curves generated based on Voce's constitutive equation in the temperature range of $300-923 \mathrm{~K}\left(27-650^{\circ} \mathrm{C}\right)$ are also depicted along with corresponding experimental $\sigma-\varepsilon$ data in Figure 4. The values of reduced $\chi^{2}$ obtained at different temperatures are listed in Table 2. These reduced Chi-Sqr values are lower than 10 for all test temperatures, which demonstrate the applicability of Voce equation for tensile flow behavior. Furthermore, no obvious correlation exists between these reduced $\chi^{2}$ values and temperatures.

Table 2. Reduced $\chi^{2}$ values obtained for Voce relationship at different temperatures for present CLAM steel at strain rate of $2 \times 10^{-4} \mathrm{~s}^{-1}$.

\begin{tabular}{cccccccc}
\hline Temperature (K) & 300 & 373 & 473 & 573 & 598 & 623 & 648 \\
Reduced $\chi^{2}$ & 8.92 & 2.34 & 0.68 & 1.36 & 3.36 & 4.35 & 0.75 \\
Temperature (K) & 673 & 723 & 773 & 823 & 873 & 898 & 923 \\
Reduced $\chi^{2}$ & 2.41 & 2.39 & 2.72 & 5.02 & 2.32 & 0.19 & 1.14 \\
\hline
\end{tabular}

The variations of work-hardening parameters, namely, saturation stress $\left(\sigma_{S}\right)$, initial stress $\left(\sigma_{I}\right)$ and rate parameter $n_{V}$, with respect to temperature for all tensile conditions are shown in Figures 5-7. Modulus compensated stress values for different temperatures are considered in present analyses to bring out the effect of temperatures, because temperatures generally influence the modulus and flow stress [24,25]. The values of Young's modulus (E) of CLAM steel at various temperatures can be obtained by a computational formula elsewhere [3]. In Figure 5, normalized saturation stress $\left(\sigma_{S} / E\right)$ with temperature reveals a marginal variation from $300 \mathrm{~K}$ to $573 \mathrm{~K}\left(27^{\circ} \mathrm{C}\right.$ to $\left.300{ }^{\circ} \mathrm{C}\right)$ followed by a plateau at intermediate temperatures of $573-673 \mathrm{~K}\left(300-400{ }^{\circ} \mathrm{C}\right)$, and finally a rapid decrease at elevated temperatures higher than $723 \mathrm{~K}\left(450{ }^{\circ} \mathrm{C}\right)$. Similarly, normalized initial stress $\left(\sigma_{I} / \mathrm{E}\right)$ with respect to temperature, as shown in Figure 6, also exhibit a marginal variation followed by a peak, and a rapid decrease in corresponding temperature ranges of variations of saturation stress. However, parameter $n_{V}$ behaves in a different manner, namely, a general marginal increase in absolute values with increasing temperatures from $300 \mathrm{~K}$ to $773 \mathrm{~K}\left(27^{\circ} \mathrm{C}\right.$ to $\left.500^{\circ} \mathrm{C}\right)$, followed by a rapid increase at temperatures of $773-873 \mathrm{~K}\left(500-600^{\circ} \mathrm{C}\right)$ and a rapid decrease in the temperature range of $873-923 \mathrm{~K}$ $\left(600-650^{\circ} \mathrm{C}\right)$, as shown in Figure 7. 


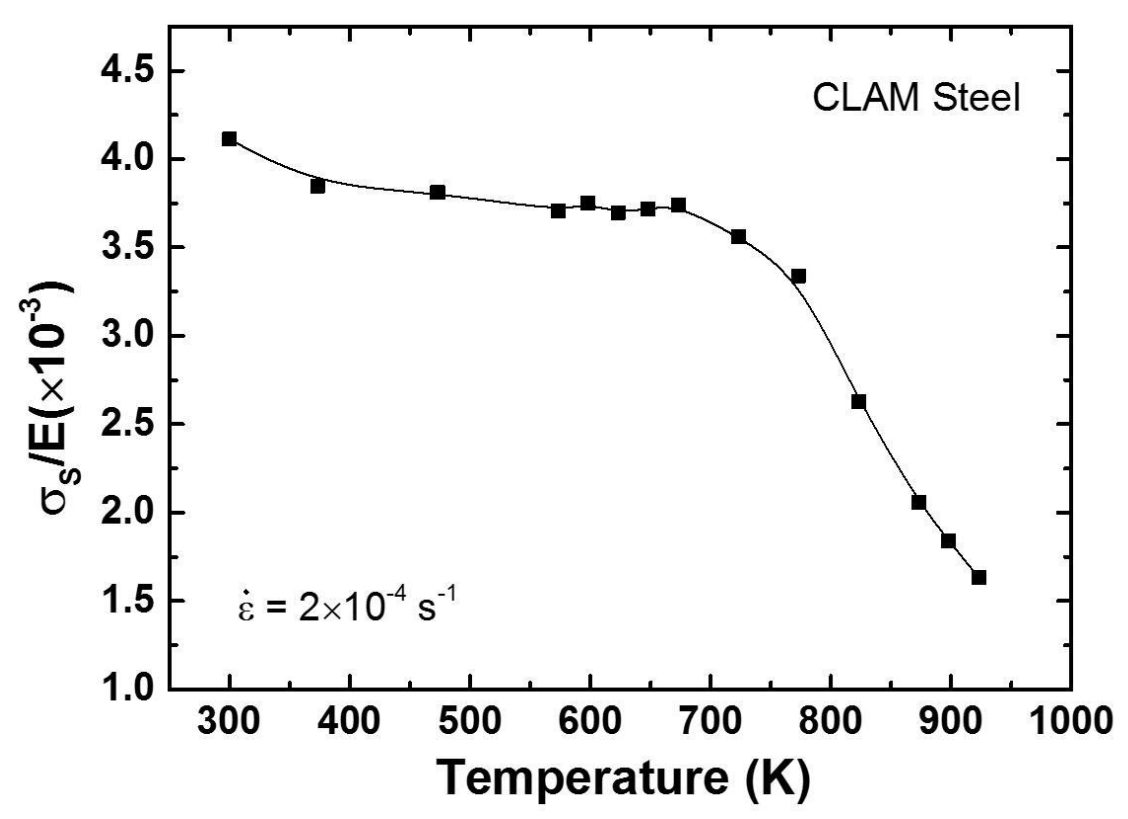

Figure 5. Variation of normalized saturation stress $\left(\sigma_{\mathrm{S}} / \mathrm{E}\right)$ with temperature at strain rate of $2 \times 10^{-4}$ $\mathrm{s}^{-1}$ in present China low activation martensitic (CLAM) steel.

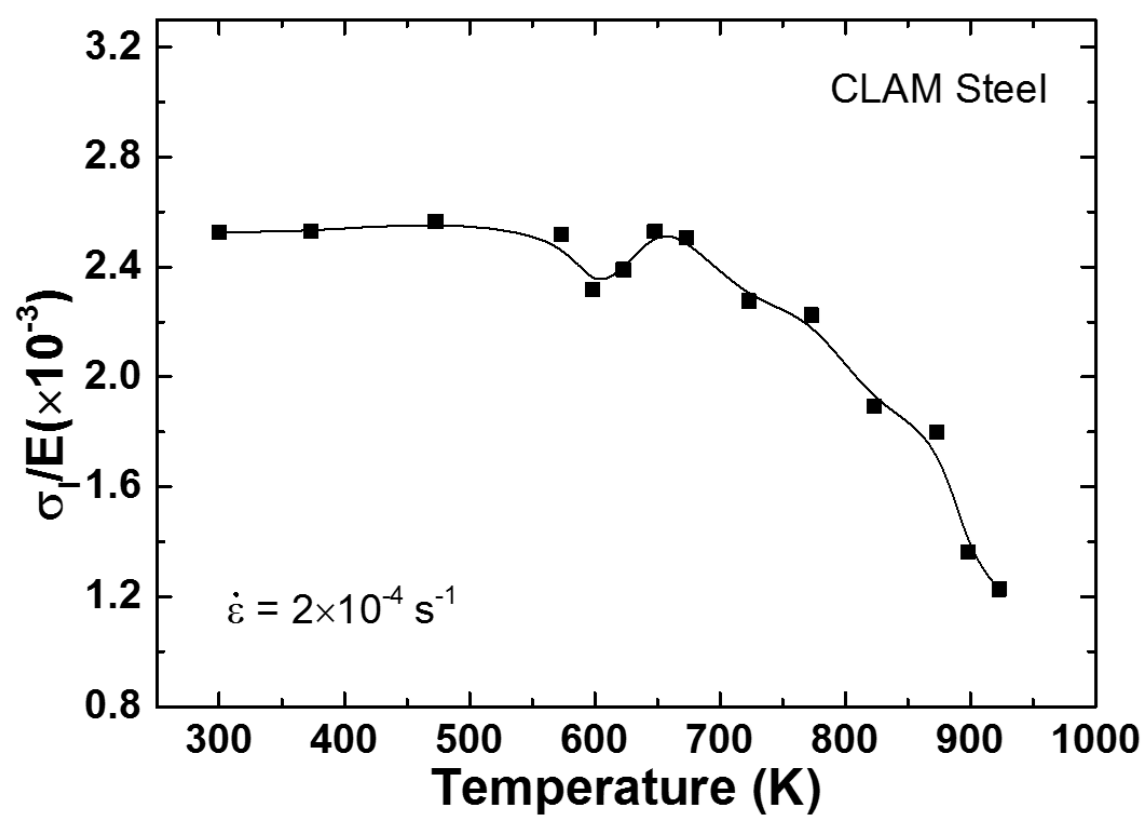

Figure 6. Variation of normalized initial stress $\left(\sigma_{I} / E\right)$ with temperature at strain rate of $2 \times 10^{-4} \mathrm{~s}^{-1}$ in present China low activation martensitic (CLAM) steel. 


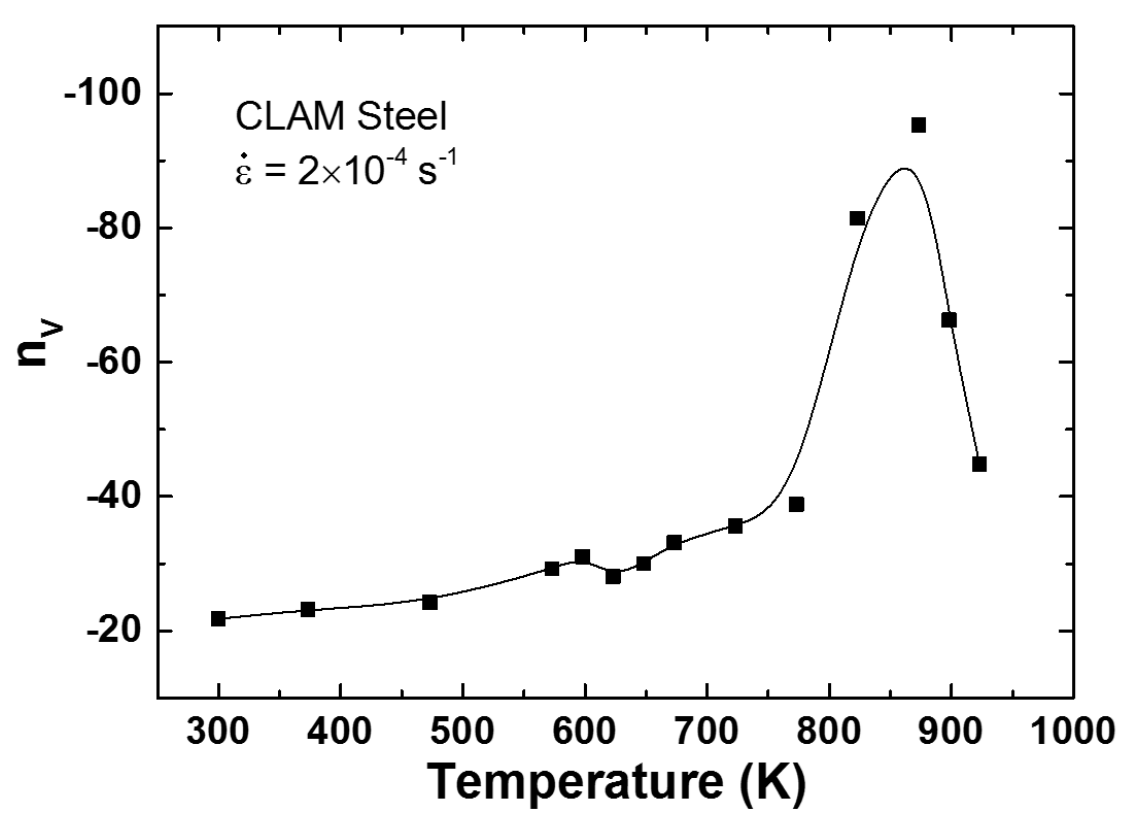

Figure 7. Variation of $n_{V}$ with temperature at strain rate of $2 \times 10^{-4} \mathrm{~s}^{-1}$ in China low activation martensitic (CLAM) steel.

Saturation stress is considered as the stress at which work-hardening rate becomes zero $(\delta \sigma / \delta \varepsilon=0)$ for some conditions like strain or temperature. In Mecking and Kocks's interpretation [21], stress saturation is a state of constancy in dislocation density and its arrangement. It has been reported that the occurrence of a plateau/peak in the values of $\sigma_{S} / E$ and $\sigma_{I} / E$ and a marginal increase in $n_{V}$ can be interpreted to DSA, as illustrated by the occurrence of serrated flow behavior at intermediate temperatures $[25,26]$. The observed rapid decrease in the values of $\sigma_{S} / E$ and $\sigma_{I} / E$ with increasing temperatures indicate the dominance of recovery processes [25-27] in the temperature range of 723-923 $\mathrm{K}\left(450-650{ }^{\circ} \mathrm{C}\right)$. However, the variations of $n_{V}$ as a function of temperature is significantly different from several previous reports for $\mathrm{F} / \mathrm{M}$ steels [24-26,34,35], in which $n_{V}$ exhibits a rapid increase with increasing temperatures in the elevated temperature range. Generally, the values of $n_{V}$ are conceded to depend on the relative contribution of glide and climb mechanisms to recovery [27], and the mechanism of climb or sub-boundary migration in the high temperature range should correspond to a large absolute value of $n_{V}$.

According to K-M formula [21,22], instantaneous work-hardening rate $(\theta=d \sigma / d \varepsilon)$ can be considered to understand tensile work-hardening behavior. Figure 8 shows the variations of $\theta$ with respect to true stress $(\sigma)$ in the temperature range of 300-923 $\mathrm{K}\left(27-650^{\circ} \mathrm{C}\right)$ for CLAM steel. At all the temperatures, $\theta-\sigma$ plots in general exhibit a rapid decrease initially in $\theta$ at relative low stresses (transient stage), subsequent to a gradual decrease at high stresses (stage-III). Following the K-M approach [21], saturation stresses can also be obtained as extrapolated stress values at $\theta=0$ from the linear portion of $\theta-\sigma$ plots in stage-III at different temperatures. A good match has been observed for saturation stresses respectively obtained from Voce equation and K-M approach $[23,27]$ in some steels. Reference $\theta=\sigma$ line is also shown as a broken line in Figure 8, which corresponds with the onset of necking at various temperatures [25]. Similar to the variations of flow, saturation and initial stresses, $\theta-\sigma$ plots also exhibits three temperature regimes. The grouping of $\theta-\sigma$ data at intermediate temperatures implies the occurrence of DSA. It should be noted that the temperature range of DSA in the present work is narrower when compared to some other previous research [5-8]. 


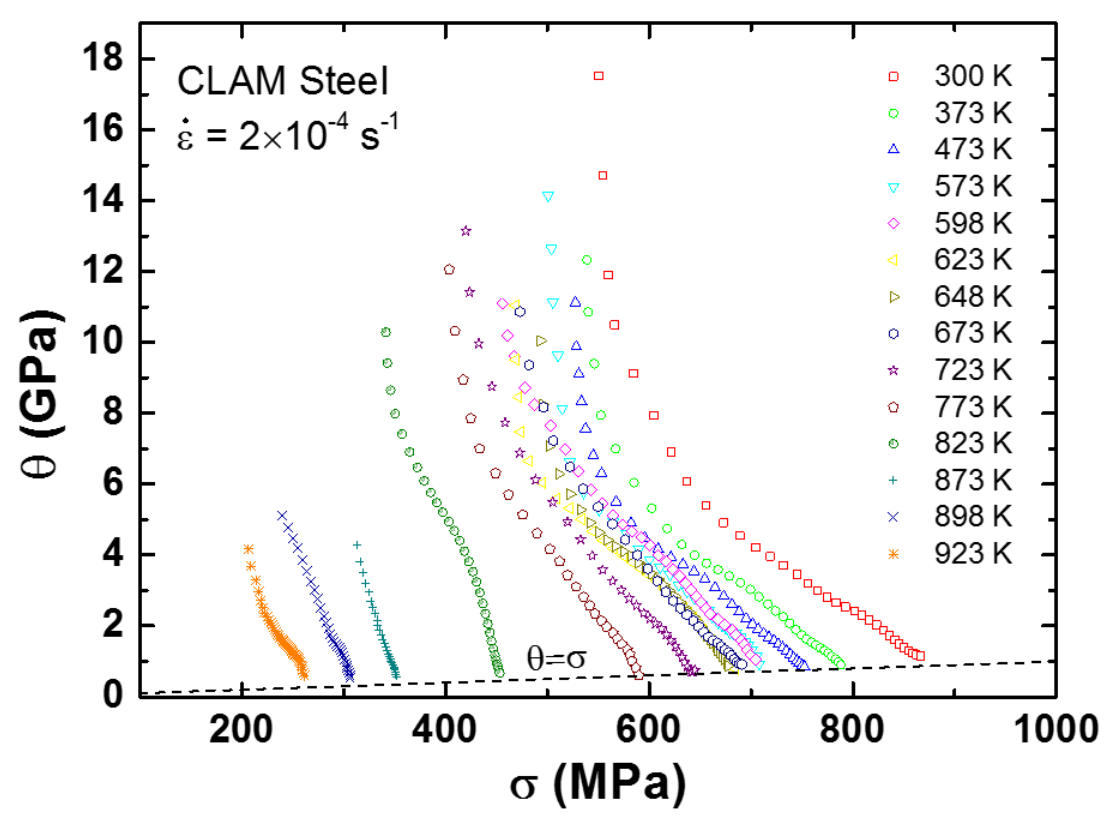

Figure 8. Variation of instantaneous work hardening rate $(\theta)$ as a function of true stress $(\sigma)$ at different temperatures in China low activation martensitic (CLAM) steel.

Applicability of Voce relationship to CLAM steel in all tensile conditions in the present investigation can be further confirmed by comparing the predicated work-hardening parameters and the ductility values (obtained from Voce equation) with the corresponding experimental results (measured from the tensile tests). A comparison of saturation stress $\left(\sigma_{S, \text { Voce }}\right)$ values obtained in the temperature range of $300-923 \mathrm{~K}\left(27-650^{\circ} \mathrm{C}\right)$ using Voce equation with the corresponding true ultimate tensile strength $\left(\sigma_{U}\right)$ values for CLAM steel is shown in Figure 9. The reference $\sigma_{S, \text { Voce }}=\sigma_{U}$ line is also shown as a full line in Figure 9. The results display a good match between $\sigma_{S}$ and $\sigma_{U}$ as $\sigma_{S, \text { Voce }} \approx \sigma_{U}$ for all tensile temperatures at strain rate of $2 \times 10^{-4} \mathrm{~s}^{-1}$ in the Voce relationship. It is accepted that $\sigma_{S, \text { Voce }}$ in the Voce equation is obtained as the asymptotic stress value after severe deformation, namely, the onset of necking $[15,20]$. According to Considere's criterion for necking, $\sigma_{U}$ is obtained as $\sigma=\sigma_{U}$ at $\theta=\sigma$, which can be obtained in $\theta-\sigma$ plot in respective temperature. The approximate equivalence of $\sigma_{S, \text { Voce }}$ and $\sigma_{U}$ is in accordance with the good fit obtained for Voce relationship in CLAM steel in Figure 4. A similar comparison of initial stress $\left(\sigma_{I, V o c e}\right)$ and true yield strength $\left(\sigma_{Y}\right)$ is shown in Figure 10. It can be seen clearly that the $\sigma_{I, V o c e}$ values are higher than the corresponding $\sigma_{Y}$. In other words, all the data points lie below the theoretical line $\sigma_{I, \text { Voce }}=\sigma_{Y}$. This result is reasonable since true yield strength $\left(\sigma_{Y}\right)$ values are the stress evaluated at an offset plastic strain of $0.2 \%$, while $\sigma_{I}$ values are obtained as the true stress at zero plastic strain. In order to further illustrate the applicability of Voce relationship for describing tensile flow behavior, a comparison between true uniform plastic strain $\left(\varepsilon_{U, V o c e}\right)$ obtained by Voce equation and experimentally observed true uniform plastic strain $\left(\varepsilon_{U}\right)$ can be made. $\varepsilon_{U, V o c e}$ values are able to be predicted by differentiating Voce equation as:

$$
\varepsilon_{U, \text { Voce }}=\frac{1}{n_{V, \text { Voce }}} \ln \left[\frac{\sigma_{S, \text { Voce }}}{\left(\sigma_{S, \text { Voce }}-\sigma_{I, \text { Voce }}\right)\left(-n_{V, \text { Voce }}\right)}\right] .
$$

when $\varepsilon=\varepsilon_{U}$ and $d \sigma / d \varepsilon=\sigma_{U} \approx \sigma_{S, V o c e}$. Figure 11 shows variations of calculated $\varepsilon_{U, V o c e}$ with experimental $\varepsilon_{U}$ at different temperatures at $2 \times 10^{-4} \mathrm{~s}^{-1}$ of CLAM steel. The theoretical line representing $\varepsilon_{U, V o c e}=\varepsilon_{U}$ is also shown as a full line in Figure 11. The results indicated a reasonable agreement between $\varepsilon_{U, V o c e}$ and $\varepsilon_{U}$ in CLAM steel. The observed approximate equivalence in Figures 9-11 between saturation stress, initial stress, and true uniform plastic strain predicted by Voce equation and corresponding experimental values is in agreement with some previous reports 
for high-Cr ferritic steel [11,24-26,31]. In addition, these observations clearly indicate the good applicability of Voce relationship for tensile flow and work-hardening behavior of CLAM steel.

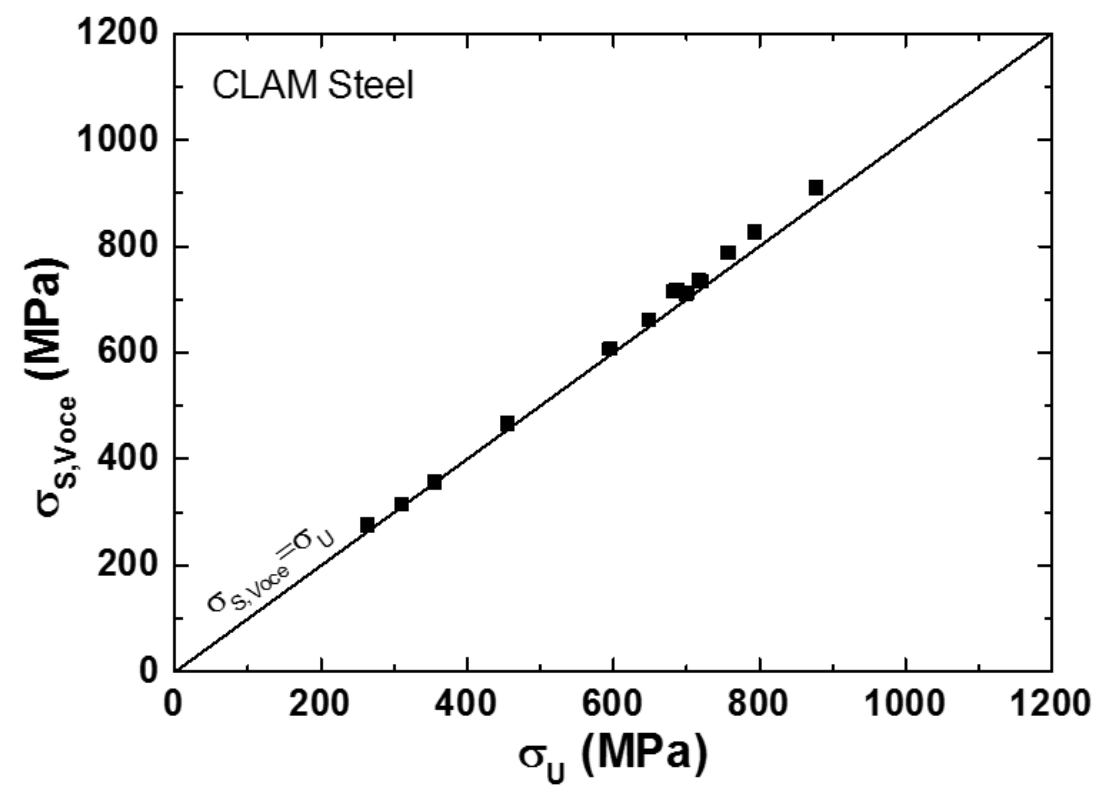

Figure 9. Comparison of saturation stress $\left(\sigma_{S, \text { Voce }}\right)$ and true ultimate tensile strength $\left(\sigma_{U}\right)$ at different temperatures in China low activation martensitic (CLAM) steel.

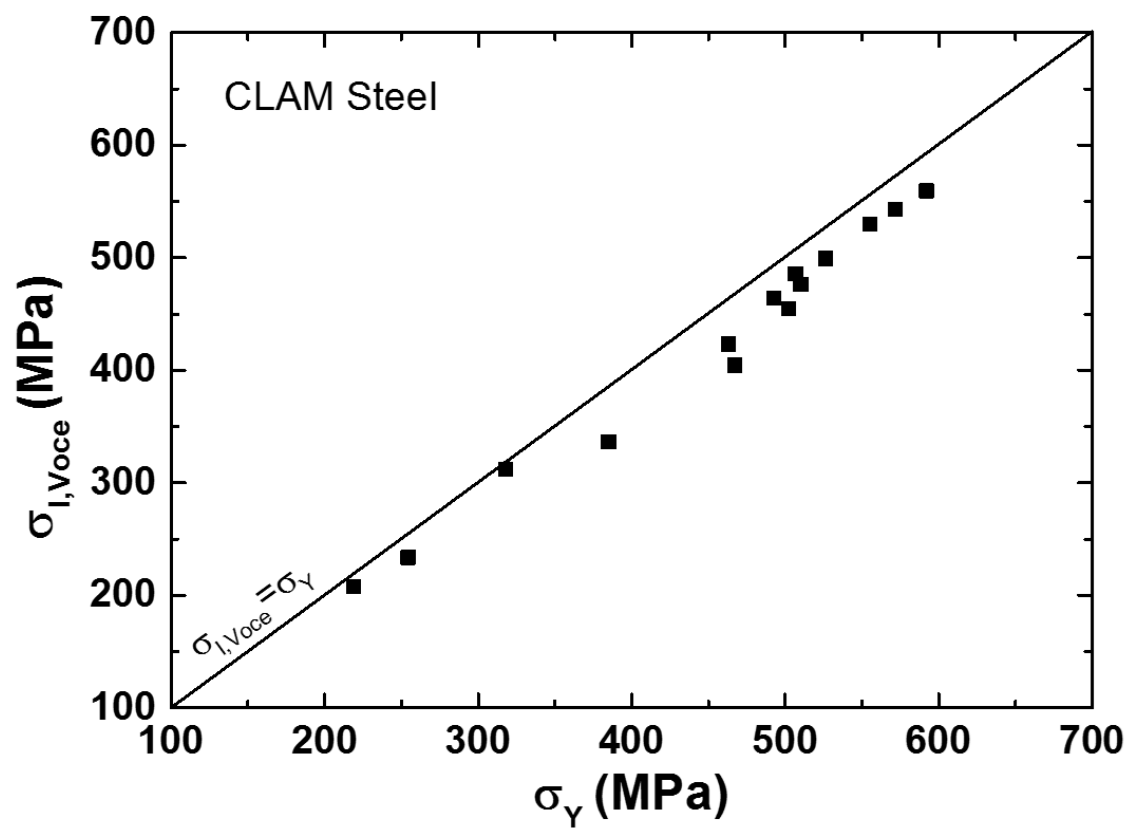

Figure 10. Comparison of initial stress $\left(\sigma_{I, V o c e}\right)$ and true yield strength $\left(\sigma_{Y}\right)$ at different temperatures in China low activation martensitic (CLAM) steel. 


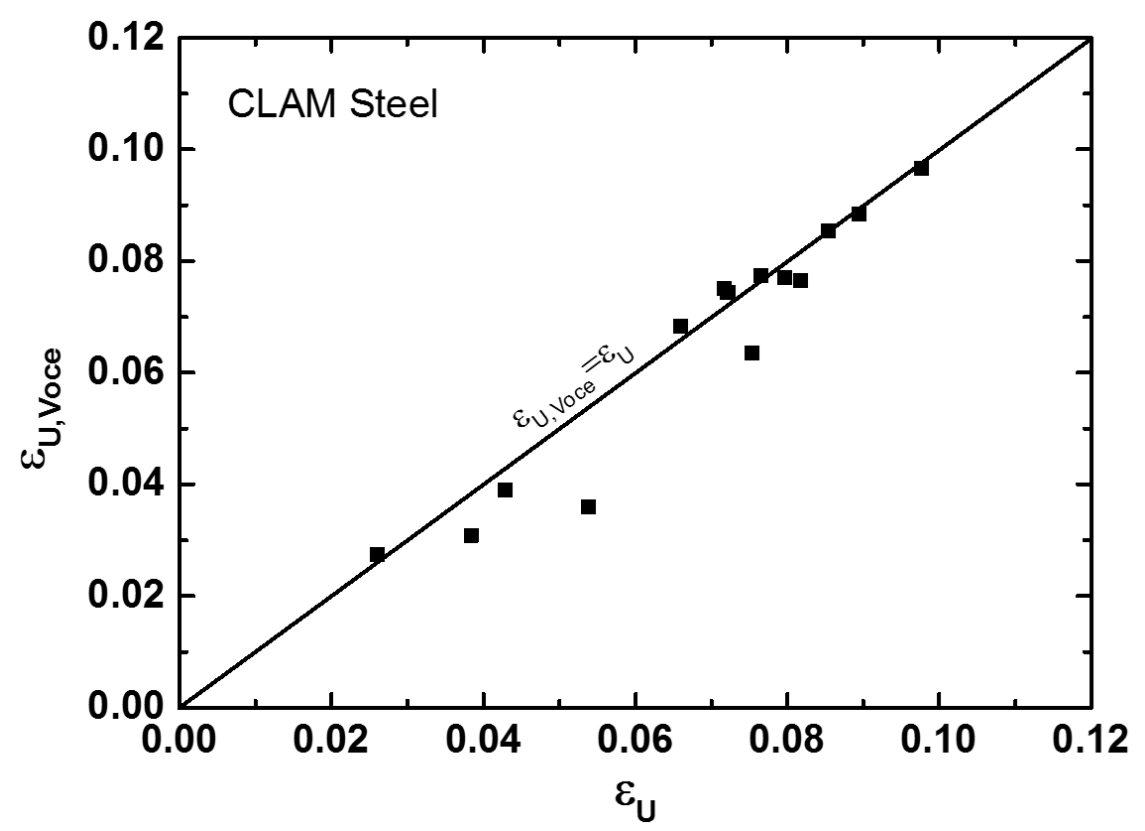

Figure 11. Comparison of predicted true uniform plastic strain $\left(\varepsilon_{U, V o c e}\right)$ and experimentally detected true uniform plastic strain $\left(\varepsilon_{U}\right)$ at different temperatures in China low activation martensitic (CLAM) steel.

The present investigation notes some limitations. On one hand, no strain gage was employed, so the critical strain method to evaluate activation energy was not successful. More tensile tests should be further carried out so that the alternate method could be used to obtain activation energy of present CLAM steel at intermediate temperatures. On the other hand, the variations of $n_{V}$ with temperatures in present CLAM steel is different from other previous reports [11,24-26,31,34,35], deserving further investigation.

\section{Conclusions}

Serrated flow and work-hardening behavior (in the frame work of Voce equation) of CLAM steel have been investigated in the temperature range of $300-923 \mathrm{~K}\left(27^{\circ} \mathrm{C}\right.$ to $\left.650{ }^{\circ} \mathrm{C}\right)$. Main conclusions are summarized as follows:

(1) Serrated flow occurs in the temperature range of 573-623 $\mathrm{K}\left(300-350{ }^{\circ} \mathrm{C}\right)$ and over $773 \mathrm{~K}$ $\left(500^{\circ} \mathrm{C}\right)$, respectively. Type $\mathrm{A}, \mathrm{A}+\mathrm{B}, \mathrm{A}+\mathrm{C}, \mathrm{A}+\mathrm{D}$ and mild serrations are identified.

(2) The occurrence of obvious serrations, a plateau in UTS, a peak in YS, and a minimum in ductility suggests the occurrence of DSA at intermediate temperatures, while the mild serrations observed at elevated temperatures are attributed to a combined effect of tensile deformation and dynamic recovery.

(3) The occurrence of a plateau/peak in the work-hardening parameters, namely, $\sigma_{S}, \sigma_{I}$ and $n_{V}$, implies the dominance of DSA at intermediate temperatures.

(4) CLAM steel in the present investigation generally displays a two-stage work-hardening behavior consisting of transient stage and stage-III.

(5) Good matches have been presented between the work-hardening parameters obtained by Voce equation and the respective experimental data of tensile properties, suggesting adequate applicability of Voce relationship for CLAM steel.

Author Contributions: Y.S. conceived and designed this experiment, and helped to analyze the data. Z.X. performed the experiments, analyzed the experimental data, and wrote the paper. 
Acknowledgments: This work was supported by the Key Program of National Natural Science Foundation of China (51034011), National Magnetic Confinement Fusion Program of The Department of Science and Technology of China (2011GB113001), and Shanghai Pujiang Program.

Conflicts of Interest: The authors declare no conflict of interest.

\section{References}

1. Bloom, E.E.; Zinkle, S.J.; Wiffen, F.W. Materials to deliver the promise of fusionpower-progress and challenges. J. Nucl. Mater. 2004, 329-333, 12-19. [CrossRef]

2. Zinkle, S.J. Advanced materials for fusion technology. Fusion Eng. Des. 2005, 74, 31-40. [CrossRef]

3. Liu, F.; Yao, M. Assessment of thermo-mechanical behavior in CLAM steel first wall structures. Fusion Eng. Des. 2012, 87, 1-6. [CrossRef]

4. Huang, Q.; Li, J.; Chen, Y. Study of irradiation effects in China low activation martensitic steel CLAM. J. Nucl. Mater. 2004, 329-333, 268-272. [CrossRef]

5. Choudhary, B.K.; Samuel, E.I.; Sainath, G.; Christopher, J.; Mathew, M.D. Influence of temperature and strain rate on tensile deformation and fracture behavior of P92 ferritic steel. Metall. Mater. Trans. A 2013, 44, 4979-4992. [CrossRef]

6. Choudhary, B.K.; Rao, K.B.S.; Mannan, S.L.; Kashyap, B.P. Serrated yielding in 9Cr-1Mo ferritic steel. Mater. Sci. Technol. 1999, 15, 791-797. [CrossRef]

7. Choudhary, B.K. Influence of strain rate and temperature on serrated flow in $9 \mathrm{Cr}-1 \mathrm{Mo}$ ferritic steel. Mater. Sci. Eng. A 2013, 564, 303-309. [CrossRef]

8. Choudhary, B.K.; Srinivasan, V.S.; Mathew, M.D. Influence of strain rate and temperature on tensile properties of 9Cr-1Mo ferritic steel. Mater. High Temp. 2011, 28, 155-161. [CrossRef]

9. Roy, A.K.; Kumar, P.; Maitra, D. Dynamic strain ageing of P91 grade steels of varied silicon content. Mater. Sci. Eng. A 2009, 499, 379-386. [CrossRef]

10. Keller, C.; Margulies, M.M.; Guillot, I. Experimental analysis of the dynamic strain ageing for a modified T91 martensitic steel. Mater. Sci. Eng. A 2012, 536, 273-275. [CrossRef]

11. Choudhary, B.K.; Palaparti, D.P.R. Comparative tensile flow and work hardening behaviour of thin section and forged thick section $9 \mathrm{Cr}-1 \mathrm{Mo}$ ferritic steel in the framework of Voce equation and Kocks-Mecking approach. J. Nucl. Mater. 2012, 430, 72-81. [CrossRef]

12. Fernández-Abia, A.I.; Barreiro, J.; López de Lacalle, L.N.; Martínez, S. Behavior of austenitic stainless steels at high speed turning using specific force coefficients. Int. J. Adv. Manuf. Technol. 2012, 62, 505-515. [CrossRef]

13. Urbikain, G.; Fernández, A.; López de Lacalle, L.N.; Gutiérrez, M.E. Stability lobes for general turning operations with slender tools in the tangential direction. Int. J. Mach. Tool Manuf. 2013, 67, 35-44. [CrossRef]

14. Martínez Krahmer, D.; Polvorosa, R.; López de Lacalle, L.N.; Alonso-Pinillos, U.; Abate, G.; Riu, F. Alternatives for Specimen Manufacturing in Tensile Testing of Steel Plates. Exp. Tech. 2016, 40, 1555-1565. [CrossRef]

15. Voce, E. A practical strain hardening function. Metallurgia 1955, 51, 219-226.

16. Voce, E. The relationship between stress and strain for homogeneous deformation. J. Inst. Met. 1948, 74, 537-562.

17. Hollomon, J.H. Tensile deformation. Trans. AIME 1945, 162, 268-290.

18. Ludwik, P. Elements der Technologischen Mechanik; Springer-Verlag Berlin Heidelberg GmbH: Leipzig, Germany, 1909; p. 32. ISBN 978-3-662-39265-2.

19. Ludwigson, D.C. Modified stress-strain relation for FCC metals and alloys. Metall. Trans. 1971, 2, $2825-2828$. [CrossRef]

20. Estrin, Y. Dislocation-density-related constitutive modeling. In Unified Constitutive Laws for Plastic Deformation; Krausz, A.S., Krausz, K., Eds.; Academic Press: San Diego, CA, USA, 1996; pp. 69-106. ISBN 978-0124259706.

21. Mecking, H.; Kocks, U.F. Kinetics of flow and strain-hardening. Acta Metall. Mater. 1981, 29, $1865-1875$. [CrossRef]

22. Kocks, U.F. Laws for work-hardening and low-temperature creep. J. Eng. Mater. Technol. 1976, 98, 76-85. [CrossRef]

23. Estrin, Y.; Mecking, H. A unified phenomenological description of work hardening and creep based on one-parameter models. Acta Metall. 1984, 32, 57-70. [CrossRef] 
24. Choudhary, B.K.; Palaparti, D.P.R.; Samuel, E.I. Analysis of tensile stress-strain and work-hardening behavior in 9Cr-1Mo ferritic steel. Metall. Mater. Trans. A 2013, 44, 212-223. [CrossRef]

25. Christopher, J.; Choudhary, B.K.; Samuel, E.I.; Srinivasan, V.S.; Mathew, M.D. Tensile flow and work hardening behaviour of $9 \mathrm{Cr}-1 \mathrm{Mo}$ ferritic steel in the frame work of Voce relationship. Mater. Sci. Eng. A 2011, 528, 6589-6595. [CrossRef]

26. Sainath, G.; Choudhary, B.K.; Christopher, J.; Samuel, E.I.; Mathew, M.D. Applicability of Voce equation for tensile flow and work hardening behaviour of P92 ferritic steel. Int. J. Pres. Ves. Pip. 2015, 132-133, 1-9. [CrossRef]

27. Shastry, C.G.; Mathew, M.D.; Rao, K.B.S.; Mannan, S.L. Analysis of elevated temperature flow and work hardening behaviour of service-exposed 2.25Cr-1Mo steel using Voce equation. Int. J. Pres. Ves. Pip. 2004, 81, 297-301. [CrossRef]

28. Kishore, R.; Sinha, T.K. Analysis of the stress-strain curves of a modified 9Cr-1Mo steel by the voce equation. Metall. Mater. Trans. A 1996, 27, 3340-3343. [CrossRef]

29. Sivaprasad, P.V.; Venugopal, S.; Venkadesan, S. Tensile Flow and Work-Hardening Behavior of a Ti-Modified Austenitic Stainless Steel. Metall. Mater. Trans. A 1997, 28A, 171-178. [CrossRef]

30. Samuel, E.I.; Choudhary, B.K.; Rao, K.B.S. Influence of temperature and strain rate on tensile work hardening behaviour of type $316 \mathrm{LN}$ austenitic stainless steel. Scr. Mater. 2002, 46, 507-512. [CrossRef]

31. Choudhary, B.K.; Christopher, J.; Palaparti, D.P.R.; Samuel, E.I.; Mathew, M.D. Influence of temperature and post weld heat treatment on tensile stress-strain and work hardening behaviour of modified 9Cr-1Mo steel. Mater. Des. 2013, 52, 58-66. [CrossRef]

32. Podriguez, P. Serrated plastic flow. Bull. Mater. Sci. 1984, 6, 653-663. [CrossRef]

33. Pink, E.; Grinberg, A. Serrated flow in a ferritic stainless steel. Mater. Sci. Eng. 1981, 51, 1-8. [CrossRef]

34. Vanaja, J.; Laha, K.; Sam, S.; Nandagopal, M.; Selvi, S.P.; Mathew, M.D.; Jayakumar, T.; Kumar, E.R. Influence of strain rate and temperature on tensile properties and flow behavior of a reduced activation ferritic-martensitic steel. J. Nucl. Mater. 2012, 424, 116-122. [CrossRef]

35. Vanaja, J.; Laha, K.; Nandagopal, M.; Sam, S.; Mathew, M.D.; Jayakumar, T.; Kumar, E.R. Effect of tungsten on tensile properties and flow behaviour of RAFM steel. J. Nucl. Mater. 2013, 433, 412-418. [CrossRef]

36. McCormick, P.G. A model for the Portevin-Le Chatelier effect in substitutional alloys. Acta Metall. 1972, 20, 351-354. [CrossRef] 